\title{
AGGRESIVE SURGICAL TREATMENT IN GERVICAL TUMOR WITH MULTIPLE LOWER ABDOMINAL DISSEMINATIONS
}

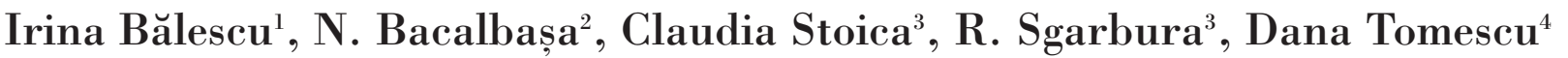 \\ 1 "Ponderas" Hospital, Bucharest, Romania \\ 2“Carol Davila” University of Medicine and Pharmacy, Bucharest, Romania \\ 3"Ilfov" County Hospital, Bucharest, Romania \\ ${ }^{4}$ Department of Anesthesia and Intensive Care III, Fundeni Clinical Institute Bucharest Romania
}

\begin{abstract}
In cases with advanced cervical cases, with large lymph node metastases or solitary peritoneal masses the patient is candidate rather for debulking surgery than systemic treatments. Several studies have proven that radiotherapy is inefficient for tumoral masses larger than $2 \mathrm{~cm}$. In this case report we present a 55 years old patient with advanced cervical cancer, large lymph node metastasis and a solitary peritoneal mass. A radical hysterectomy with bilateral adnexectomy,lymph node dissection and mesosigmoid mass resection were performed. The patient was addressed to adjuvant chemotherapy.
\end{abstract}

Key words: advanced cervical cancer, large lymph node metastases, debulking surgery, irradiation

\section{Introduction}

Cervical cancer is the second most common malignancy among women worldwide. There are still a large number of patients who are diagnosed in an advanced stage of the disease (III, IVA). Preoperative routine evaluation prior to decide which the appropriate treatment planning is includes $\mathrm{CT}$ and MRI of abdomen and pelvis. If large tumoral masses are found (lymph node metastases or peritoneal masses), the patient is candidate for debulking surgery, and later submitted to adjuvant systemic therapy.

\section{Case report}

We present a 55 years old patient who was addressed to our service for persistent vaginal bleeding associated with pelvic pain. The local gynecologic exam showed a large cervical mass, invading the left parameter. The biopsies revealed nonkeratinized squamous moderately differentiated carcinoma. The CT scan showed a large cervical mass measuring $14 / 10 \mathrm{~cm}$ with large peritoneal masses (left iliac fossa and infra-renal para-aortic). Due to the extracervical presence of disease the multidisciplinary board decided to perform per primam debulking surgery; radical total hysterec- 
tomy with bilateral adnexectomy, with pelvic, interaortico-caval, para-aortic lymph node dissection; the tumoral mass in the mesosigmoid was also resected. (fig. 1-7) Resection of the mesosigmoid mass required ligature at the origin of the inferior mesenteric artery; however, the integrity of the marginal arcade was preserved, so no colic resection was necessary. A special mention needs to be made concerning the lymphodissection: the patient presented with a large retro-aortic lymph node, which was approached for resection after complete dissection and mobilization of the aorta, achieved by ligation and section of two lumbar arteries. The postoperative evolution was uneventful, the patient was discharged in the 10th postoperatively day and she started the adjuvant oncologic treatment 2 weeks later.

\section{Discussions}

The 2 main patterns of spread for cervical cancer are lymphatic channels and direct local invasion; while the second pathway can be relatively easy managed by the radical surgical treatment, the first one is more frequent and represents a poor prognostic factor associated with higher rates of fatal recurrence. (1) The most common sites of metastases are pelvic and para-aortic lymph nodes, and both of them worsen the prognosis. (2-6)

In order to obtain a better survival in these cases, lymph node metastases can be treated by radiotherapy if they are recognized before surgery or by debulking surgery if they are found intraoperatively. It seems that the two modalities of treatment report the same curative rate for small tumoral masses, while their combination leads to an increased morbidity with no benefit on survival $(2,6,7,8)$. According to radio-biological studies, a $2 \mathrm{~cm}$ mass needs 60 Gy of external beam radiotherapy to be sterlised in $90 \%$ proportion and 75 Gy to achieve $100 \%$ control, this dose being intolerable for the surrounding organs. (9) A higher dose of irradiation can not be administrated to the para-aortic area. In these cases surgical debulking via laparotomy or laparoscopy before adjuvant chemo-irradiation proved to be efficient $(1,2,3,5,10-17)$

In Potish's study, 159 patients with advanced cervical cancer underwent surgery prior to radiotherapy; the 5 year relapse free survival ranged between $86 \%$ in patient with resectable pelvic lymph node metastases to $0 \%$ in cases with

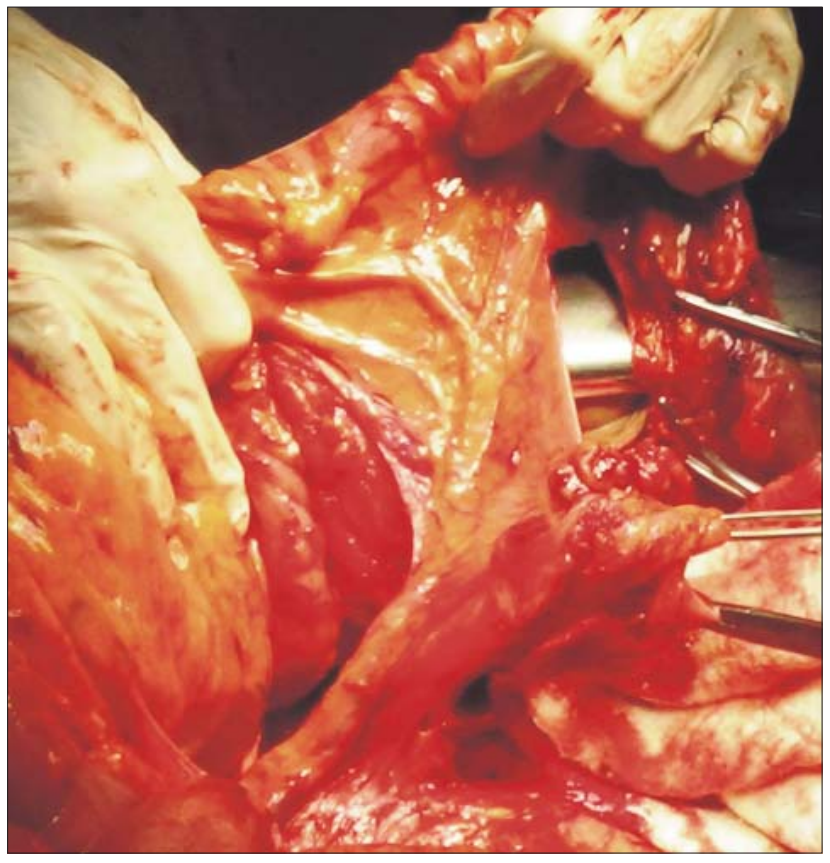

Figure 1 - Large tumoral mass in the mesosigmoid

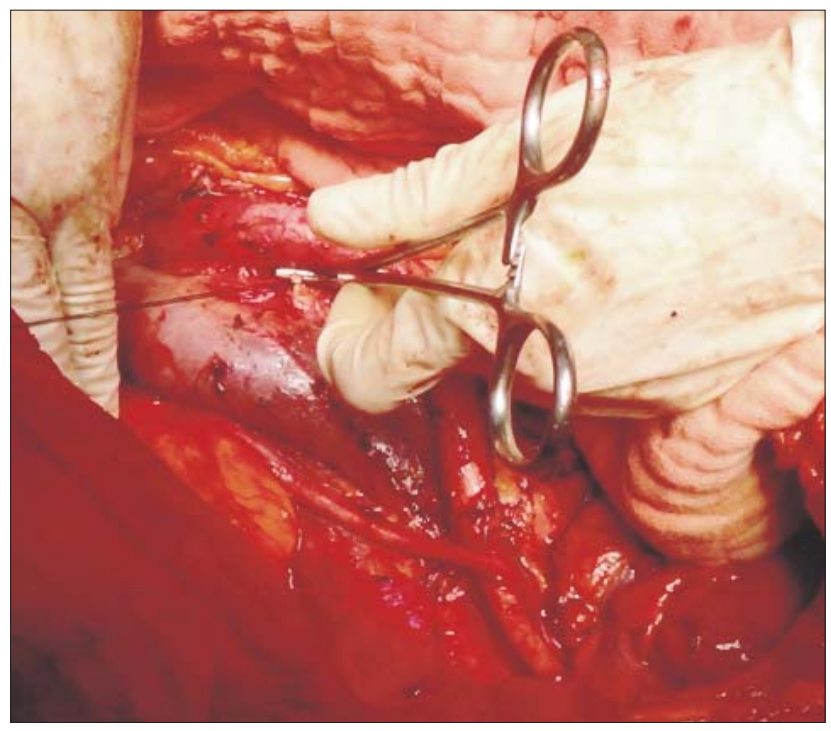

Figure 2 - Sectioning of a lombar artery

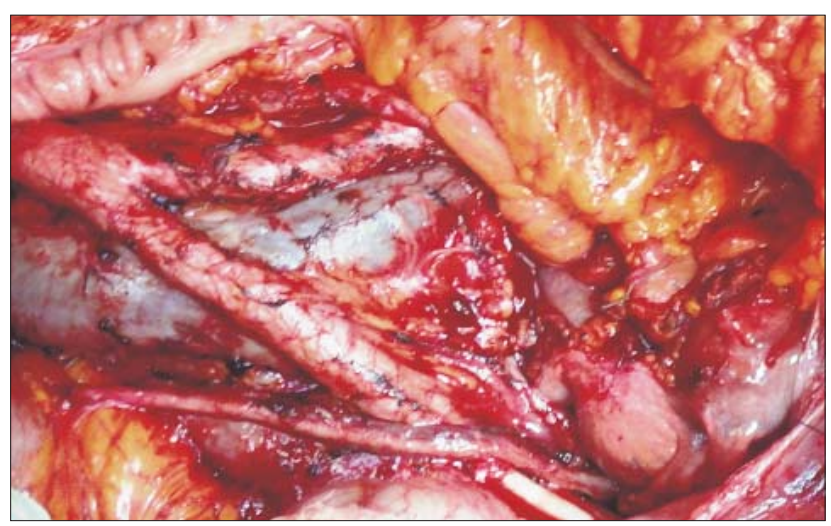

Figure 3 - Inter-aortico-caval and iliac bilateral lymph node dissection 


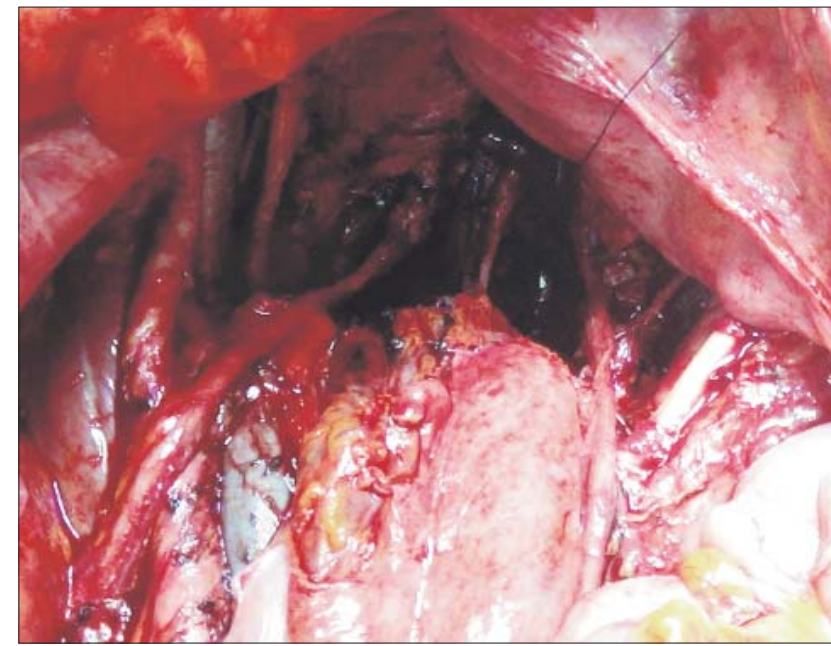

Figure 4 - The final aspect after radical hysterectomy with bilateral adnexectomy and pelvic lymph node dissection

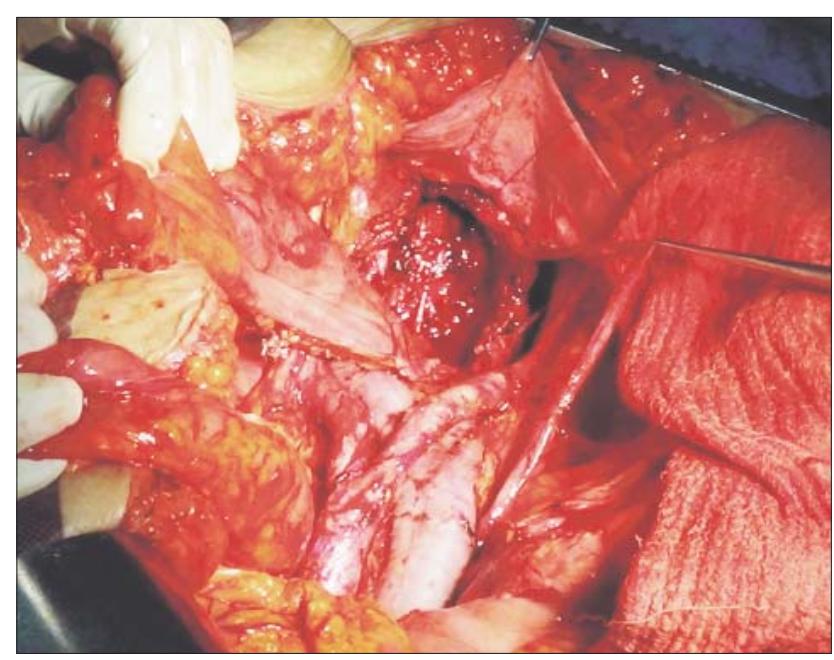

Figure 6 - The final aspect after pelvic and inter-aorticocaval lymph node dissection

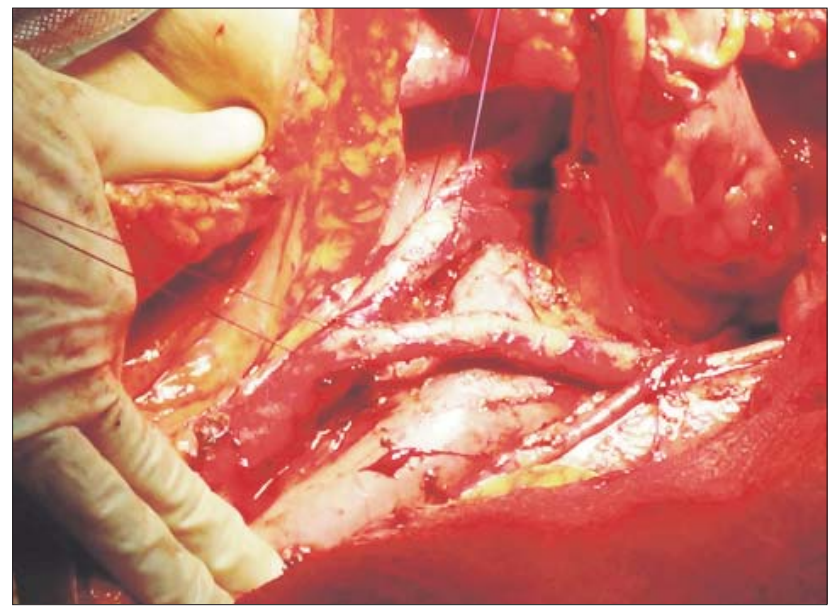

Figure 5 - The final aspect after removing a large retroaortic lymph node metastasis: both the left common iliac artery and abdominal aorta are completely dissected

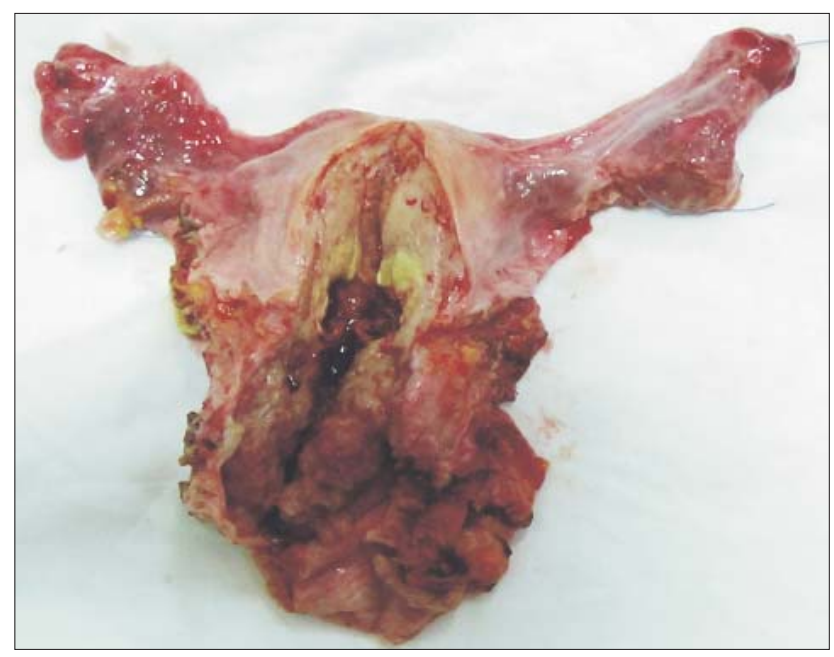

Figure 7 - The specimen of total hysterectomy with bilateral adnexectomy presenting a large cervical tumor

microscopic lymph node metastases). (11) At the other pole we find the patients with large adenopathies which could not be resected; in this group the 3 year overall survival is situated between 0-3\%) $(11,12)$.

Zighelboim et al tried to determine which are the specific parameters that could be considered as prediction factors of success in the surgical ablation prior to systemic therapy (chemoirradiation). The patient's age, the size of the largest lymph node and its' location seemed to be the most important factors. Elderly patients, with lymph node metastasis larger than $2 \mathrm{~cm}$, invading the vascular structures, the bones and those located above the superior mesenteric artery had a worse outcome. (6) 
The presence of peritoneal tumoral masses is also an important factor predicting the relapse of the disease. Sometimes it cannot be seen in preoperative investigations (CT,MRI) and is an intraoperatory finding (6). Debulking surgery, either for large adenopathies or for peritoneal masses seems to make sense; the microscopic tumoral tissue left behind will be now easier managed by the systemic adjuvant therapy.

\section{Conclusions}

While radio-biological studies are trying to increase the radiation dose to the target organ and spare the adjacent structures by using intensity modulated radiotherapy, surgery remains the best option for patients with cervical cancer associated with bulky lymph node. (2)

Removing large metastatic lymph nodes and solitary peritoneal masses before systemic chemoirradiation seems to improve the disease free interval and overall survival in cervical cancer, but prospective randomized studies and longer followup periods are still needed.

\section{References}

1. O'Hanlan, K., Comprehensive, therapeutic retroperitoneal pelvic and infrarenal aortic lymphadenectomy for advanced cervical carcinoma, Gynecologic Oncology 130 (2013) 634-635

2. Tozzi, R., Lavra, F., Cassese, T., Campanile, R.,Pedicini, V., Bignardi,M., Scorsetti, M., Bertuzzi, A., Laparoscopic debulking of bulky lymph nodes in women with cervical cancer: indication and surgical outcomes, DOI: 10.1111/j.14710528.2008.02032.x, Gy

3. Morice P, Castaigne D, Pautier P, Rey A, Haie-eder C, Leblanc $\mathrm{M}$, et al. Interest of pelvic and paraaortic lymphadenectomy in patients with stage IB and II cervical carcinoma. Gynecol Oncol 1999;73:106-10.

4. Delgado G, Bundy B, Zaino R, Sevin BU, Creasman WT, Major F. Prospective surgical-pathological study of diseasefree interval in patients with stage IB squamous cell carcinoma of the cervix: a Gynecologic Oncology Group study. Gynecol Oncol 1990;38:352-7.

5. Goff BA, Muntz HG, Paley PJ, Tamimi Hk, Koh WJ, Greer BE. Impact ofsurgical staging in women with locally advanced cervical cancer. Gynecol Oncol 1999;74:436-2.na

6. Zighelboim 11, Ramirez PT, Gao F, Slomovitz BM, Sun C, Frumovitz M, Jhingran A, Levenback C., Retroperitoneal lymph node resection in patients with cervical cancer, Surg Oncol. 2006 Aug;15(2):79-83. Epub 2006 Oct 10.

7. Rutledge FN, Fletcher GH, Macdonald EJ. Pelvic lymphadenectomy as an adjunct to radiation therapy treatment for cancer of the cervix. American Journal of Roentgenology 1965;93:607-14.

8. Wharton JT, Jones HW, Day TG, Rutledge FN, Fletcher GH. Preirradiation celiotomy and extended field irradiation forinvasive carcinoma of the cervix. Obstetrics and Gynecology 1977;49:333-8.cal

9. Perez CA, Hall EJ, Purdy JA, Williamson J. Biologic an physical aspects of radiation oncology. In Hoskins WJ, Perez CA, Young RC, editors. Gynecologic Oncology, 2nd edn. Philadelphia, PA: Lippincott-Raven; 1997. pp. 305-80.onc

10. oHacker NF, Wain GV, Nicklin JL. Resection of bulky positive lymph nodes in patients with cervical carcinoma. Int J Gynecol Cancer 1995;5:250-6.

11. Cosin JA, Fowler JM, Chen MD, Paley PJ, Carson LF, Twiggs LB. Pretreatment surgical staging of patients with cervical carcinoma: the case for lymph node debulking. Cancer 1998;82:2241-8.

12. Potish RA, Downey GO, Adcock LL, Prem KA, Twiggs LB. The role of surgical debulking in cancer of the uterine cervix. Int $J$ Radiat Oncol Biol Phys 1989;17:979-84.

13. Downey GO, Potish RA, Adcock LL, Prem KA, Twiggs LB. Pretreatment surgical staging in cervical carcinoma: therapeutic efficacy of pelvic lymph node resection. Am J Obstet Gynecol 1989;160(Pt 1):1055-61.y

14. Kim PY, Monk BJ, Chabra S, Burger RA, Vasilev SA, Manetta $A$, et al. Cervical cancer with paraaortic metastases: significance of residual paraaortic disease after surgical staging. Gynecol Oncol 1998;69:243-7.

15. Kinney WK, Hodge DO, Egorshin EV, Ballard DJ, Podratz KC. Surgical treatment of patients with stages IB and IIA carcinoma of the cervix and palpably positive pelvic lymph nodes. Gynecology and Oncology 1995;57:145-9.

16. Fine BA, Hempling RE, Piver MS, Baker TR, McAuley M, Driscoll D. Severe radiation morbidity in carcinoma of the cervix: impact of pretherapy surgical staging and previous surgery. International Journal of Radiative Oncology, Biology and Physics 1995;31:717-23.

17. Kenter GG, Hellebrekers BW, Zwinderman KH, van de Vijver M, Peters LA, Trimbos JB. The case for completing the lymphadenectomy when positive lymph nodes are found during radical hysterectomy for cervical carcinoma. Acta Obstetrics and Gynecology of Scandinavia 2000;79:72-6 